\title{
UM VERGER, DOIS OLHARES: a construção da africanidade brasileira por um estrangeiro
}

\author{
Maurício Barros de Castro* \\ Myrian Sepúlveda dos Santos**
}

\begin{abstract}
As reflexões sobre o olhar estrangeiro têm sido frequentes nas últimas décadas, principalmente a partir da crítica à formação de um imaginário repleto de exotismo e sensualidade associado aos trópicos. Não é, portanto, exagero afirmar que o problema das representações, usos e abusos da imagem dos afrodescendentes no Brasil, ao longo dos séculos, permanece como foco importante para se entender a história das relações raciais no país. Nem sempre, contudo, procura-se o exótico nos trópicos. Este artigo procura analisar o impacto do olhar de Pierre Verger sobre a construção do legado africano no Brasil.
\end{abstract}

PALAVRAS-CHAVE: Pierre Verger. Afrodescendentes. Relações raciais.

\section{INTRODUÇÃO: fotografias e suas coleções}

Este artigo teve início com a inquietação dos autores surgida a partir da edição da coluna social de um dos maiores jornais do país que, em certo sábado de 2013, trouxe uma página inteira dedicada ao "Tipo Carioca", ${ }^{1}$ tendo por base fotografias de Pierre Verger tiradas no Rio de Janeiro, provavelmente em 1941. Quatro fotografias ganharam destaque. A foto maior, situada no centro da página, reproduzia um encontro entre duas mulheres negras em um morro carioca. Uma delas - chamada, na coluna, de Maria Lata D’água - carregava na cabeça uma lata de banha de porco, utilizada, na época, para cozinhar. A mulher, sorridente, afagava uma criança, que, por sua vez,

* Universidade do Estado do Rio de Janeiro. Instituto de Artes. Programa de Pós-graduação em Artes (PPGARTES). Rua São Francisco Xavier, $524-11^{\circ}$ andar - bloco E. Cep: 20550-900. Maracanã - Rio de Janeiro - Rio de Janeiro Brasil. barrosdecastro@yahoo.com.br

** Universidade do Estado do Rio de Janeiro. Pós-Graduação em Ciências Sociais.

Rua São Francisco Xavier, 524, sala 9001, bloco A. Cep: 20550-900. Maracanã - Rio de Janeiro - Rio de Janeiro Brasil. myrian.sepulveda.santos@gmail.com

${ }^{1}$ Trata-se da coluna Gente Boa, publicada no Segundo Caderno do Jornal O Globo, em 16.3.2013, p. 3. encontrava-se no colo da outra mulher com quem conversava. Abaixo, duas fotos menores mostravam o retrato, respectivamente, de um homem e de uma mulher, ambos sorridentes, trajando roupas de domingo em um parque da cidade. Numa foto ainda menor, no meio da coluna lateral direita, dois salva-vidas posavam na praia, usando boina e cinto. Embora todos os personagens pudessem ser identificados como negros, pelos padrões identitários brasileiros, a matéria jornalística associou as fotografias de Verger aos "tipos cariocas", como a "Maria Lata D’Água” e os salva-vidas, apresentando-os como personagens do cotidiano da cidade, adaptados à vida urbana.

Acostumados com a obra do fotógrafo francês Pierre Verger, cujas imagens das religiões afro-brasileiras tornaram-se mundialmente famosas, percebemos que a dimensão de "negritude" ou "africanidade" de suas fotos não havia sido destacada. Como veremos adiante, o fotógrafo francês fez parte de um grupo de intelectuais que se notabilizou por destacar as influências africanas sobre práticas religiosas e culturais encontradas no Brasil. Através de suas fotografias e de sua atuação no 
cenário intelectual e político, Verger exerceu grande influência na construção de um país que, aos poucos, vem modificando seus imaginários coletivos e reconhecendo as contribuições da cultura africana.

Em que pese a intenção do artista, as fotografias trazem, com elas, diversos significados. Além disso, elas são apropriadas de diferentes formas pelo público em geral. Como afirmou o historiador Martin Lienhard (2006, p. 218) a respeito da obra do fotógrafo moçambicano Sergio Santimano, "Independente da vontade dos fotógrafos, as mesmas fotos, portanto, autorizam discursos ou interpretações diversas". Considerando que as imagens sempre nos dão algum testemunho, para além da intencionalidade de seu autor, procuramos investigar se havia o sentido de oposição entre Rio de Janeiro e Salvador no conjunto de fotografias deixado por Pierre Verger, bem como o impacto de seu olhar na construção dessa oposição.

A citada coluna do jornal fazia propaganda de uma exposição de fotos de Pierre Verger, organizada pelo curador Mario Cohen, em um dos corredores do mezanino do Hotel Copacabana Palace. Nessa exposição, foram dispostas, em duas fileiras, oito fotos do Rio de Janeiro e oito fotos de Salvador. Dentre as fotos do Rio de Janeiro, duas foram apresentadas pelo jornal: os o salva-vidas de boina e cinto e a jovem sorridenते te em sua roupa de domingo. As demais tinham como tema banhistas na praia de Copacabana; สี carnavalescos pendurados no bonde da linha (7) Cascadura; e três fotografias de paisagens (Pão c de Açúcar, Corcovado e Copacabana). Diferentemente do que dizia a matéria jornalística, as o fotos não estavam centradas em "tipos cario\& cas"; exceto pela foto da jovem sorridente, as ơ demais foram tiradas a certa distância, de modo a envolver os personagens ao seu entorno. A exposição trazia fotos da paisagem carioca. $\mathrm{Na}$ segunda fileira, estavam as fotos tiradas em Salvador. Nelas, em contraste com as do Rio, foi dado um destaque bem maior a expressões, olhares, e gestos de homens negros, quase todos jovens, que tinham por fundo o trabalho da pesca, o mar, as redes, as velas e os saveiros. A maior parte das fotos retratava, portanto, pescadores e marinheiros da cidade de Salvador à pequena distância. Apenas uma das fotos retratava mulheres conversando, e, mesmo assim, elas se posicionavam de costas para a máquina fotográfica.
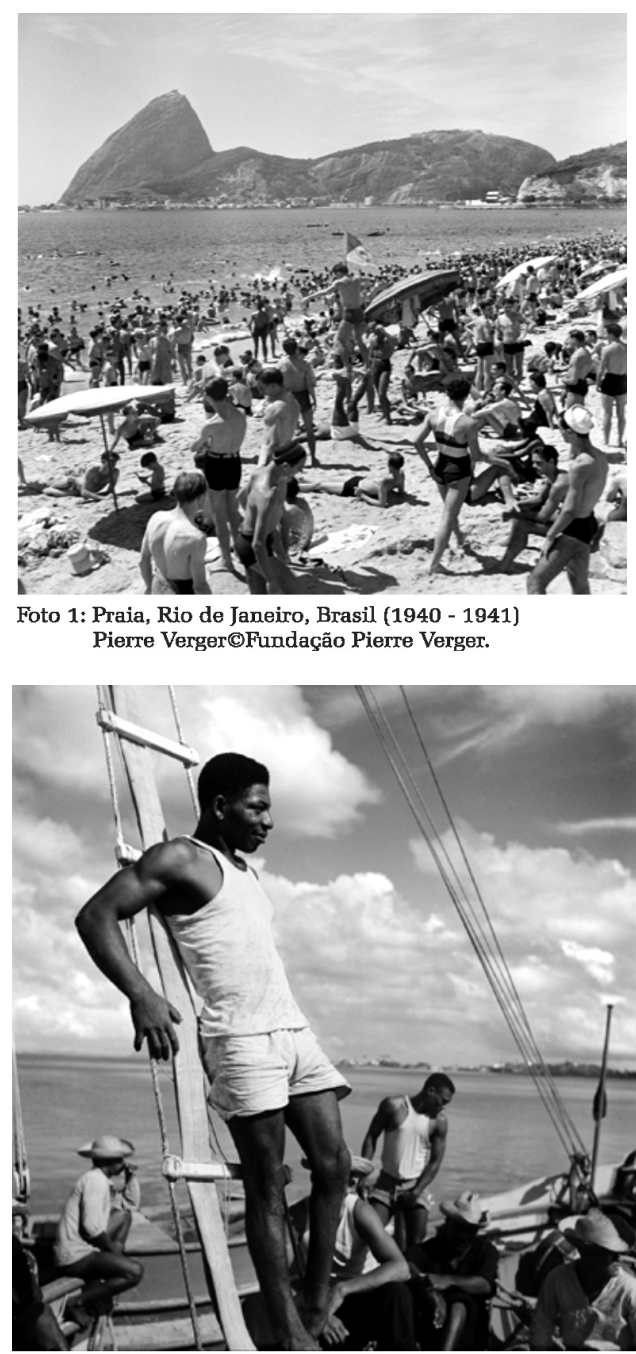

Foto 2: Porto, Salvador, Brasil (Anos 50). Pierre Verger (CFundação Pierre Verger.

A exposição, de pequena circulação e aberta em um dos hotéis mais luxuosos da cidade, não era destinada ao grande público. Certamente, seu objetivo era a venda das fotos, que faziam parte de uma galeria de arte localizada nas proximidades do hotel. De qualquer forma, a exposição contrastava o olhar do fotógrafo francês para as duas cidades. Sem dúvida, as fotos colocavam em oposição os mora- 
dores do Rio de Janeiro, vestidos formalmente e aparentemente adaptados ao cotidiano da cidade, e aqueles de Salvador, em roupas sumárias e em contato direto com o mar. A partir da exposição, ficou a dúvida se esse duplo olhar que separava as cidades de Salvador e do Rio de Janeiro estava presente em Verger, ou se fora construído pelo curador da exposição.

Alguns esclarecimentos preliminares precisam ser feitos. Não temos a intenção de, neste breve espaço, apresentar uma trajetória de vida detalhada de Verger, o que já tem sido feito com competência por outros estudos (Lühning, 1998-9, 2002 e Souty, 2011), mas apontar seu pertencimento a um grupo de intelectuais franceses e brasileiros, bem como alguns fatos e eventos que marcaram sua chegada tanto ao Rio de Janeiro como a Salvador. Também não é nosso objetivo desenvolver um estudo comparativo sobre a maior ou menor influência de práticas culturais e religiosas de matriz africana no Rio de Janeiro e em Salvador. Esses são estudos presentes no trabalho de diversos antropólogos e historiadores (Bastide 1960, Alencastro 2000), bem como do próprio Verger (Verger 1968). A terceira observação é a de que partimos do pressuposto de que os conceitos de negritude e africanidade aqui tratados são construções inerentes a determinados processos sociais e históricos. Independentemente da maior ou menor presença de remanescentes da cultura africana em Salvador, ela pode tanto ser silenciada como se apresentar sob a forma de discursos e representações variados. Este é nosso campo de pesquisa.

Assim sendo, a partir de uma compreensão maior do contexto de época, das relações existentes entre intelectuais brasileiros e estrangeiros, nosso objetivo é melhor compreender o olhar de Verger sobre Rio de Janeiro e Salvador, bem como o papel desempenhado pelo artista na valorização do significado da herança africana para os brasileiros. Na primeira sessão, foi analisada a formação de fotógrafo de Pierre Verger. Nas duas sessões seguintes, o foco recaiu sobre a trajetória intelec- tual do fotógrafo e a rede de relações mantidas ao longo de sua vida. A última parte do artigo volta-se para a relação entre as seleções das fotos expostas em Copacabana e no jornal carioca e o conjunto da obra de Verger, tendo como contrapartida o acervo fotográfico da Fundação Pierre Verger, localizada em Salvador.

\section{UMA TRAJETÓRIA, UM OLHAR: a fotografia como registro}

No artigo do antropólogo Raul Lody sobre o "olhador do mundo", citações de Verger sobre a fotografia se alternam com as de Roland Barthes (apud Lody, 2001, p. 11). Segundo esse último:

[...] a fotografia separa a atenção da percepção, e liberta apenas a primeira, todavia impossível sem a segunda; trata-se, coisa aberrante, de uma noese sem noema, um ato de pensamento sem pensamento, uma mirada sem alvo. No entanto, é esse movimento escandaloso que produz a mais rara qualidade de um ar.

O Pierre Verger fotógrafo tem sido descrito por seu desapego às técnicas de pesquisa e pelo olhar desprendido que não procurava compreender, nem explicar. Há uma aura em torno da fotografia e de sua capacidade de fixar o real em detrimento das intenções daquele que tem a máquina em suas mãos.

Para o próprio Verger (apud Lody, 2002, p. 11), a fotografia poderia ser equiparada a um ato de pensamento sem pensamento.

Consciente ou inconsciente, queria era fazer as minhas fotos. Digo inconscientemente, porque tem grande parte do inconsciente quando se faz uma foto. Você faz uma foto e não sabe por que. Depois, na ampliação, descobre a coisa que você viu sem ter tempo de interpretar.

Esse "ato de pensamento sem pensamento", contudo, fez parte de uma abordagem teórica que se fortaleceu na primeira metade do século passado. Pierre Verger iniciou sua carreira de fotógrafo com a idade de trinta anos, quando se desligou da família e passou a viajar pelo mundo com sua máquina Rolleiflex. Isso aconteceu 
em 1932. Vinculado a agências fotográficas, rodou o mundo como correspondente de diversos jornais e revistas. Após uma pequena viagem à Rússia, partiu para as ilhas do Pacífico, viajando do Taiti até a Ilha de Páscoa. Em 1934, fez a volta ao mundo, passando pelos Estados Unidos, canal do Panamá, Japão, China e Filipinas. No ano seguinte, viajou pela Espanha de bicicleta. Entre 1934 e 1940, Verger foi membro de uma agência fotográfica de prestígio, a Alliance Photo, e foi colaborador de diversos jornais e revistas: Paris-Soir, em 1934; Daily Mirror, em 1935-36; Life, em 1937; e Match, em 1938. Entre 1935 e 1937, Verger trabalhou para o Musée d'Ethnographie du Trocadéro (Musée de l'Homme, em 1937), instituição dirigida por Paul Rivet e voltada para o estudo e difusão da diversidade cultural. Verger passou a se interessar pela etnografia após seu contato com esse museu, que foi o primeiro de caráter etnográfico a ser fundado em Paris (Rego, 1993). O impacto do encontro de Pierre Verger com o grupo de pensadores que participava das atividades do Museu do Trocadéro não foi pequeno. Ele manteve intenso diálogo ao longo de sua vida com esses intelectuais que, como veremos, exerceram uma grande influência sobre seu pensamento. Não é por acaso que sua primeira viagem à África foi em 1936.

O Museu do Trocadéro foi criado com o objetivo de preservar as coleções obtidas peస los viajantes franceses que eram enviados aos diversos continentes com missões colonizado-

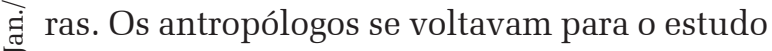
. das sociedades ditas "primitivas". O sucesso da exposição de objetos oriundos da África, Ásia, América e Oceania, na Exposição Universal o de 1878, facilitou a criação do museu. Ernest \& Hamy, seu primeiro diretor, ao descrever as co今 leções que foram agregadas pelo museu, des-

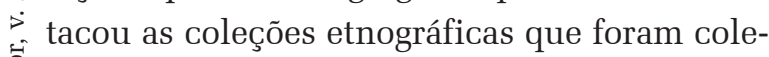
tadas a partir do reinado de Luís XVI (Hamy, 1980). Apesar de as exposições procurarem mostrar a evolução contínua da humanidade segundo a perspectiva científica da época, narrativas e coleções de objetos sempre trazem múltiplos sentidos e podem ser apropriadas de diferentes maneiras. Os objetos expostos pelo museu atraíam novos olhares. Nas primeiras décadas do século XX, teorias evolucionistas começaram a ser criticadas pelos próprios etnógrafos. Em outra vertente, a arte primitiva passou a fazer parte dos movimentos artísticos cubistas e fauvistas, que procuravam uma mediação entre a realidade e forças sociais hostis. Diversos artistas, entre eles o jovem Picasso, foram influenciados pelos objetos expostos no Museu do Trocadéro. Artistas ligados ao movimento surrealista também prestigiaram as coleções expostas, colaborando com os etnólogos, apesar de seus interesses estarem vinculados à perspectiva estética dos objetos. ${ }^{2}$

O Museu do Trocadéro foi fechado durante a Primeira Guerra Mundial, sendo reaberto em 1928, já com uma perspectiva antievolucionista, a partir das atividades de Paul Rivet e Georges Henri-Rivière. Dez anos mais tarde, também após o evento de uma Exposição Universal, o Museu do Homem foi criado, tendo à frente Paul Rivet e agregando às coleções do antigo museu as coleções de antropologia física do Museu Nacional de História Natural. O museu tornou-se conhecido por preservar a cultura material das sociedades não ocidentais. ${ }^{3}$

Para Paul Rivet, as coleções do museu tinham o compromisso de apresentar ao público a diversidade cultural e social presente nas civilizações mundiais. Embora de formação médica, ele desempenhou um importante papel, junto com Marcel Mauss e Lucien Lévy-Bruhl, entre outros, na criação de um laboratório de pesquisa, na Universidade de Paris, que envolvia a antropologia, a etnologia e a pré-história. Revitalizou o ensino da etnologia, substituindo a antropologia física por abordagens culturais e humanistas. Investiu sistematicamente

${ }^{2}$ Em 2006, o Museu do Quai Branly foi inaugurado com cerca de 300 mil peças da coleção etnográfica do Museu do Homem, gerando muita controvérsia pelos critérios estéticos adotados para a apresentação dos objetos selecionados.

${ }^{3} \mathrm{Na}$ reorganização do acervo museológico, as coleções relacionadas à arte popular francesa foram transferidas para o Museu Nacional de Artes e Tradições Populares, sendo Rivière seu primeiro diretor. 
no estudo das línguas dos diversos povos, defendendo uma visão difusionista e procurando aprofundar o horizonte histórico das sociedades não ocidentais. Foi um defensor incansável da ideia de que todos os homens possuíam igual capacidade inventiva e criadora. ${ }^{4}$ Em torno, primeiro, do Museu do Trocadero e, depois, do $\mathrm{Mu}$ seu do Homem, havia, portanto, um importante grupo de intelectuais que se destacou tanto por renovar os estudos etnográficos como pela defesa de uma agenda antifascista e antirracista.

Os princípios adotados por Verger, em suas fotografias, não estavam distantes daqueles empregados pelos seus amigos etnógrafos em seus trabalhos de campo. Para ele, a fotografia deveria expressar a cumplicidade e o jogo travado entre o fotógrafo e aquele que seria fotografado. A grande quantidade de closes tirados por Verger mostra que havia uma proximidade muito grande entre seu olhar e o do "outro". Sua fotografia, mais do que um momento, registrava uma relação. Podemos, dessa forma, compreender a afirmação de Verger de que sua intenção era fotografar sem ter hipóteses sobre seu objeto, evitando perguntas. Ele se interessava por captar sorrisos, rostos, expressões que se encontravam nos portos, nas ruas, nos bairros e em festas populares. Diferentemente da tradição mantida no campo fotográfico, seu objetivo não era produzir uma foto de composição; ele negligenciava o lado estético em prol das expressões e cenas com que mantinha contato. O fotógrafo se excluía de qualquer movimento artístico, raramente expunha seus trabalhos e se mostrava pouco interessado pelo destino e pelo uso de seus negativos. Seus enquadramentos eram incomuns: cortava cabeças e corpos. Suas fotos eram inclinadas. Verger procurava ressaltar uma silhueta, uma expressão, sentimentos. Para os etnógrafos, foi justamente essa abordagem, sem predeterminações e sem a preocupação estética, que lhe permitiu uma liberdade ímpar na arte de captar imagens. ${ }^{5}$

\footnotetext{
${ }^{4}$ Para mais detalhes sobre a trajetória profissional e política de Paul Rivet, ver Laurière 2007.

${ }^{5}$ Para uma análise do olhar fotográfico de Verger, ver tanto
}

Nas palavras de Alfred Métraux, por exemplo, a etnografia deveria ser destituída de teoria, ou seja, de sistemas de conceitos exteriores aos fatos observados (Lühning 2004, p. 63). Esses pensadores defendiam, em alternativa às teorias que os antecediam, a resistência a teorias pré-concebidas no desenvolvimento do trabalho de campo e a diversidade apresentada nas práticas culturais de povos não europeus. Tratava-se, sem dúvida, de uma guinada teórica que procurava se desvencilhar de antigos estereótipos e preconceitos incorporados às atividades ditas científicas. Embora a nova abordagem procurasse, de alguma forma, revelar o "real", sem intermediações, ela, evidentemente, não era destituída de princípios teóricos. A renovação teórica que ocorria entre antropólogos tinha pontos de contato com outros movimentos de artistas, literatos e cineastas, que rejeitavam teorias pré-concebidas e procuravam, nas obras de arte, um valor que lhes fosse intrínseco.

Verger compartilhou, portanto, o mesmo interesse que estava presente em um grande número de intelectuais de sua época: apresentar ao mundo, através de um novo olhar, os povos não europeus em sua diversidade sociocultural. Como foi pontuado por Baradel (2002), as fotografias feitas por Verger ofereciam um verdadeiro ar fresco e novo para o público europeu, acostumado às fotografias que ilustravam os trabalhos etnológicos anteriores, invariavelmente carregadas de preconceitos coloniais e raciais.

Com a chegada da Segunda Guerra Mundial e o genocídio de milhões de judeus e ciganos em nome da pureza racial, lideranças intelectuais e políticas abandonaram ou foram expulsas do continente. Paul Rivet foi demitido de suas funções pelo governo de Vichy, fez parte da resistência francesa e foi para o exílio na Colômbia, em 1941. Os países da América Latina tornaram-se refúgio para muitos desses exilados, inclusive para Verger. Esse último, depois de passar por alguns países da América Lody (2002) como Baradel (2002). 
Latina, visitou as cidades de São Paulo e Rio de Janeiro, procurando um trabalho que lhe permitisse ficar no Brasil. Já se encontrava no Rio de Janeiro Marcel Gautherot, também um fotógrafo francês que fora associado ao Museu do Homem. Gautherot se dedicava às paisagens, tinha um comprometimento estético mais apurado, e acabou por se integrar ao círculo de intelectuais brasileiros ligados ao modernismo, que incluía Mario de Andrade, Lucio Costa, Burle Marx, Carlos Drummond de Andrade e outros. Foi nesse período, portanto, isto é, em 1941, que Verger chegou ao Rio de Janeiro e tirou suas fotos tanto de paisagens como de festas e bairros populares.

Como vimos anteriormente, a dimensão estética não era priorizada por Verger, que se encontrava bem próximo das abordagens etnográficas e da valorização da diversidade cultural. Segundo declarações suas, ao chegar ao Brasil, ele já havia lido Jubiabá, de Jorge Amado, obra que fora traduzido na França com o título de Bahia de tous-les-saints, e que divulgava, pelo mundo, as tradições religiosas de matriz africana encontradas em Salvador (Rego, 1993). O romance conta a história de Antonio Balduíno, um herói popular, negro e pobre, que tira sua força de Jubiabá, o pai de santo do Morro do Capa Negro, que trazia sempre um ramo de folhas e resmungava palavras em nagô. Jubiabá S estava à frente dos rituais de candomblé, rezava os doentes que o procuravam, produzindo a สี cura, e representava, para Balduíno, a liberdade gु e a sabedoria das florestas africanas, uma vez que a maior parte dos negros que morava no morro havia sido submetida às leis da escravió dão, dos senhores brancos e ricos.

म É importante destacar que, na década de 今 1940, o Brasil atraía a atenção de intelectuais e de estrangeiros que procuravam se distanciar das teses eurocêntricas e evolucionistas e procuravam compreender a "democracia racial" existente no país. Nesse contexto, assumia uma maior importância a presença da cultura africana no Brasil. Em 1937, foi organizado, em Salvador, o II Congresso Afro-Brasileiro, que se tornou um marco para seus praticantes. Participaram do Congresso tanto os representantes dos grandes candomblés da Bahia como intelectuais envolvidos com sua defesa, entre eles os brasileiros Edson Carneiro e Arthur Ramos, conhecidos por seus estudos sobre religiões de matriz africana, e os antropólogos norte-americanos Donald Pierson e Melville Herskovits.

Quando Verger chegou ao Brasil, encontrou o regime autoritário de Getúlio Vargas, que estava em vigor desde 1937, e uma situação política tensa. Jorge Amado, por exemplo, membro do Partido Comunista, saíra do país, procurando exílio na Argentina e no Uruguai. Assim, após passar pelo Rio de Janeiro, em 1941, Verger deixou a cidade e foi para Buenos Aires, colaborando com os jornais Argentina Libre e Mundo Argentino. Esteve no Peru, entre 1942 e 1946, associado ao Museu Nacional de Lima. Em 1946, já com o regime democrático instalado, voltou ao Brasil, e, após uma breve passagem pelo Rio de Janeiro, fixou residência em Salvador, num quarto de hotel na cidade alta, atualmente centro histórico, com vista para os telhados da cidade baixa e para o mercado. Para estabelecer-se no país, foi importante a obtenção da proposta de trabalho em O Cruzeiro, revista de grande circulação, para a qual contribuiu com suas fotos até 1951. Já instalado em Salvador, partiu para o nordeste em busca de reportagens e iniciou o conjunto de travessias entre Brasil e África, que foram mantidas ao longo de sua vida.

\section{INTÉRPRETE DOS CULTOS E TRA- DIÇÕES AFRICANAS DE SALVADOR}

Eu me deixei tomar completamente pela questão dos cultos e tradições africanas na Bahia. É como se eu estivesse enfeitiçado e dedico-me quase que exclusivamente a isto desde o meu retorno (Carta de Verger para Alfred Métraux de 24/01/1948. Acervo Fundação Pierre Verger).

Uma vez finda a Segunda Guerra Mun- 
dial, em 1945, Paul Rivet assumiu novamente a direção do Museu do Homem e dedicou-se às investigações sobre América Latina, defendendo o lugar do índio nas diversas nações andinas e posicionando-se contra o racismo. Também no ano de 1945, a Organização das Nações Unidas (ONU) foi formada. Três anos depois, foi proclamada a Declaração Universal dos Direitos dos Homens, que afirmou que todos os seres humanos, sem distinção, nomeadamente de raça, de cor, de sexo, de língua, de religião, de opinião política ou outra, nascem livres e iguais em dignidade e direitos. Práticas discriminatórias em termos de raça tornaramse mais difíceis de legitimação pela ciência ou por políticas de Estado. No campo intelectual, combatia-se o racismo "científico", isto é, teorias que afirmavam a superioridade biológica ou genética da população europeia. Data desse período, o fortalecimento de movimentos nacionalistas africanos, que foram responsáveis pela independência de diversas nações coloniais. Fazia parte da agenda desses movimentos, lado a lado do direito à autodeterminação, a retomada dos mitos, dos rituais e dos orixás africanos, que haviam sido substituídos pelos deuses dos povos colonizadores. Certamente, toda essa conjuntura política teve repercussões no olhar de Pierre Verger sobre o Brasil, país em que os cultos religiosos de matriz africana estavam presentes e eram duramente reprimidos.

Em 1946, ano em que Verger se instalou em Salvador, foi criada a Federação Baiana do Culto Afro-Brasileiro, constituída por 35 terreiros. A cultura popular que girava em torno dos veleiros, com seus capoeiristas, tambores e rituais religiosos, atraía artistas e intelectuais, e Verger logo se tornou parte de um círculo seleto. O músico Dorival Caymmi e a cantora e atriz Carmem Miranda, de diferentes maneiras, divulgaram a cultura dos mercados e dos veleiros do Recôncavo para fora do país. Carybé, pintor, desenhista e gravador argentino naturalizado brasileiro, especializou-se na representação dos orixás e terreiros religiosos aos quais ele pertencia. O escritor Jorge Amado tornou-se um dos maiores defensores do candomblé baiano. ${ }^{6}$ Segundo Mãe Stella de Oxóssi:

Jorge Amado, ateu que acreditava em Oxóssi, escolhido como Obá de Xangô no Ilê Opô Afonjá, foi para nós um sacerdote 'ministro da Justiça' que atuou de maneira marcante, uma vez que foi através dele que o candomblé passou a ser constitucionalmente visto como religião, o que fez com que seus adeptos não precisassem mais pedir licença à polícia para adorar Olorum - o Grande Criador - e os Orixás - as divindades auxiliares (Fundação Pierre Verger, 2012, p. 34).

Tal como Jorge Amado, Carybé e outros tantos intelectuais, Verger, embora agnóstico, adotou o candomblé, passando a admirar a imensa liberdade de sentimentos entre seus participantes. Em 1948, conheceu D. Maria Bibiana do Espírito Santo, Mãe Senhora, a Yalorixá do Ilê Axê Opô Afonjá, o que foi determinante em sua vida. A partir da autodeterminação dos povos africanos, os cultos proporcionavam a seus adeptos o orgulho por suas origens e conferiam dignidade a seus participantes, que passavam a ser respeitados por serem herdeiros de tradições orais e mitos marcados por complexidade e riqueza de detalhes. Para toda uma geração de intelectuais, provar a africanidade desses cultos representava uma postura política, pois desafiava as teorias eurocêntricas que postulavam a fácil assimilação das culturas "inferiores" pelas europeias.

Pierre Verger manteve, ao longo de sua vida, uma troca de correspondências bastante significativa com Alfred Métraux e Roger Bastide, intelectuais com formação na França e com vários interesses em comum. Os encontros e as trocas de correspondência entre esses três intelectuais estão fartamente documentados. ${ }^{7}$ O que queremos ressaltar desses encontros é o interesse comum que tinham esses autores em ${ }^{6}$ Em 1947, o Partido Comunista Brasileiro (PCB) foi colocado na ilegalidade, e Jorge Amado procurou exílio na França, e nas antigas Tchecoslováquia e União Soviética, retornando ao Brasil apenas em 1954. Fixou residência no Rio Vermelho, em Salvador, apenas em 1961, quando já se encontrava consagrado como escritor da cultura afro-baiana.

${ }^{7}$ Ver, por exemplo, Métraux/Verger 1994; Lühning 2002a; Lühning 2004. 
compreender a presença "africana” no Brasil.

Nos anos de 1950 e 1951, foi organizado um grupo de pesquisa, patrocinado pela Organização das Nações Unidas para a Educação, Ciência e Cultura (UNESCO) e voltado para o estudo das relações raciais no país. O projeto fora proposto inicialmente por Arthur Ramos, no final dos anos 40. Após sua morte, coube ao antropólogo Alfred Métraux, membro permanente do Departamento de Ciências Sociais da UNESCO, coordenar a pesquisa, que foi dividida entre regióes. Entre os colaboradores do projeto estava Roger Bastide, que havia chegado ao Brasil em 1938, para ocupar a cadeira deixada por Lévi-Strauss e organizar a Faculdade de Filosofia, Ciências e Letras da Universidade de São Paulo. Entre os intelectuais brasileiros, destacaram-se Thales de Azevedo, Oracy Nogueira, Costa Pinto e Gilberto Freyre. Embora, na elaboração inicial do projeto, Métraux, estivesse preocupado em detectar possíveis formas de manifestação do racismo no país, em artigo publicado em 1951, apontou não só a forte presença da cultura "africana" em Salvador, como caracterizou a Bahia como terra mestiça, reiterando a crença de que não havia, no país, problemas de natureza racial, mas social. ${ }^{8}$

Nos anos de 1951 e 1952, Bastide e o sociólogo paulista Florestan Fernandes desenvol- veram uma pesquisa sobre relações raciais em ㄱ. São Paulo. A pesquisa apontou uma integração dos indivíduos de cor às classes médias, uma สี vez que os autores compreenderam que os proque assinalavam que a industrialização não representava rompimento com o passado e que havia a convivência entre sobrevivências da sociedade escravista e inovações da sociedade capitalista. Tal tema foi desenvolvido nos tra-

${ }^{8}$ Sobre a formação do projeto UNESCO e seus desdobramentos no Brasil, ver Maio, 1999. balhos subsequentes. ${ }^{9}$

Bastide retornou à França em 1954, e defendeu sua tese de doutorado sobre as religiões "africanas" no Brasil em 1958. Publicou, em seguida, O candomblé da Bahia (1958) e Religiões Africanas no Brasil (1960). Nesses estudos, analisou o encontro entre África e Brasil, argumentando que, embora a escravidão tivesse destruído a possibilidade de transmissão dos mitos africanos, ou seja, das estruturas mais complexas presentes do outro lado do Atlântico, os africanos se reorganizaram na colônia, a partir de práticas rituais que reproduziam costumes arcaicos, ainda que sem a plena consciência de seu significado. A partir da construção da distância entre as duas linguagens, a dos mitos e a dos rituais, já estabelecida por Lévi-Strauss, ${ }^{10}$ Bastide propôs a tese de que o empobrecimento da mitologia africana no Brasil não seria resultado nem do esquecimento nem da coerção de outros grupos sociais, mas, sim, da ausência de estruturas que possibilitassem sua reconstrução plena. Os legados "africanos" encontrados no Brasil eram aqueles reproduzidos pelos escravos que chegavam ao novo continente, quando eles conseguiam adaptar estruturas simbólicas anteriores, ainda que fragmentadas, às novas condições de vida. Para Bastide, o que estava em questão, no encontro entre duas culturas, era o grau de complexidade de estruturas africanas em solo brasileiro, e não mais a superioridade de uma cultura sobre outra.

\section{FLUXOS E REFLUXOS: para além da interpretação}

A escolha de Verger por Salvador e o desdobramento de seu trabalho foram ante-

${ }^{9}$ Ver Bastide e Fernandes 1955. Ainda para uma análise sobre obra de Roger Bastide, ver Peixoto 2000.

10 Ver a apresentação de Lévi-Strauss, de 26 de maio de 1956, sobre a relação entre a mitologia e o ritual, seguida de debate com diversos participantes, entre outros Louis Dumont, Alfred Métraux, Jacques Lacan, Maurice Merleau-Ponty e Lucien Goldmann. Philosophie des sciences, 699-722. http://pt.scribd.com/doc/27390069/Levi-StraussSur-les-rapports-entre-la-mythologie-et-le-rituel, acessado em 15/04/2013. 
cedidos por encontros, indicações e contatos fornecidos por Métraux e Bastide. Após 1946, Verger e Métraux se encontraram, algumas vezes, tanto na Bahia como na África. Dois anos após chegar a Salvador, Verger realizou suas primeiras viagens para o antigo Daomé e a Nigéria, em busca das "fontes" do candomblé da Bahia, cuja pesquisa se tornou o seu principal foco. Entre 1949 e 1960, Verger fez treze travessias entre Rio de Janeiro e Dakar, chegando a cruzar o Atlântico até duas vezes por ano (Lühning, 2002a). Seu conhecimento sobre os cultos religiosos no Brasil e na África tornouse fundamental para seus amigos antropólogos. Em 1951, Bastide visitou, junto com Verger, alguns terreiros de candomblé, entre eles, o Terreiro Ilê Axé Opô Afonjá. Bastide também fez uma longa viagem à África tendo Verger como guia (Lühning, 2002a e Lühning, 2004).

A partir de 1953, a obra de Verger deixou de ser apenas fotográfica, desdobrando-se em análises históricas e etnográficas sobre as mútuas ligações entre os dois lados do Atlântico. Em sua tese, Flux e reflux de le traite des esclaves entre le Golfe du Bénin et Bahia de Todos os Santos, du dix-septième au dix-neuvième siècle, Verger apresentou uma importante documentação histórica acerca do trânsito bilateral, ocasionado pelo tráfico de escravos, entre a Bahia e os reinos e cidades africanas que se localizavam na região que abrange os atuais Togo, Benin e Nigéria, países que fazem parte do Golfo da Guiné. Defendida em 1966 na Sorbonne, a pesquisa foi publicada dois anos depois na França.

O ponto de partida da pesquisa de Verger foi a cidade de Uidá no Benin, onde encontrou uma documentação composta por cartas enviadas pelo traficante de escravos José Francisco dos Santos, apelidado de "Alfaiate", devido à profissão que exercera na Bahia antes de se dedicar ao "comércio de almas" na África. Conforme explicou o próprio Verger (2002, p. 23) em relação ao objetivo de seu trabalho, "O que procuro mostrar aqui, fundamentalmente, são as conexões e influências recíprocas, sutis ou declaradas, que se desenvolveram entre as duas regiões caracterizadas na correspondência do Alfaiate".

Verger dedicou seu trabalho, como fotógrafo, pesquisador, mensageiro cultural e museólogo, ao legado das culturas nagô (ioruba) e jeje (fon), tanto na África quando no Brasil, principalmente no que diz respeito a seus aspectos religiosos. Dessa maneira, toda sua defesa das tradições africanas e de sua permanência no Brasil está focalizada nos povos do grupo linguístico ioruba e fon.

Além disso, Verger não foi apenas um estudioso das relações entre Salvador e Benin, mas participou ativamente desse intercâmbio, servindo de mediador entre as duas culturas. Nas muitas viagens que fazia entre Brasil e África, trazia encomendas para os terreiros de candomblé, objetos para o culto, plantas, tecidos, búzios, além das fotos que tirava e que serviam, para ele, como uma forma de mostrar para africanos e negros afro-brasileiros as semelhanças entre os dois mundos. Seu papel de mediador pode ser percebido também na criação do Museu Afro-Brasileiro, em 1982. A participação de Verger nesse projeto foi fundamental. Conforme explicou Souty (2011, p. 87): "Em 1975, patrocinado pelo Itamaraty, o fotógrafo-pesquisador adquiriu, na região fon e ioruba, 251 objetos e peças de artesanato destinados ao museu e promoveu o intercâmbio com outras instituições museológicas.”

O papel ativo de mediador cultural desempenhado por Verger o colocou como antagonista do proeminente antropólogo norte-americano Melville J. Herskovits, que mantinha intenso diálogo com Arthur Ramos e chegou ao Brasil, em final de 1941, para investigar a presença da cultura africana no país. ${ }^{11}$ Sua pesquisa de campo foi realizada em Porto Alegre, Salvador e Recife. Como vimos, havia, nesse período, uma agenda mundial antirracista, e

${ }^{11}$ Ver comentário de Verger em sua carta a Métraux, reproduzida em Métraux \& Verger (1994, p. 296). Sobre o tema, ver ainda Souty (2011, p. 181), segundo o qual, no fim de sua vida, Verger fez tentativas concretas para reafricanizar os cultos no Brasil, introduzindo antigas práticas africanas. 
Herskovits, diferentemente de outros intelectuais, mantinha-se fiel aos cânones acadêmicos, criticando a antropologia aplicada. ${ }^{12}$ Vinculado ao departamento de antropologia da Northwestern University, Herskovits tinha um forte suporte institucional, o que lhe permitia viajar e comparar práticas culturais africanas e aquelas difundidas no Novo Mundo, facilidade que não estava presente entre as reflexões realizadas por pesquisadores brasileiros. Discípulo do antropólogo norte-americano Franz Boas, Herskovits foi crítico, portanto, do conceito biológico de raça, interessando-se por investigar, no Brasil, práticas culturais que lhe permitissem comparar os diferentes graus do que denominou de aculturação dos africanos nas Américas. É bem conhecido seu debate com Franklin Frazier, esse último um crítico do culturalismo e defensor da tese de integração racial. ${ }^{13}$

Para Herskovits, o que tornava Salvador importante, como campo de pesquisa, era o fato de os laços da cidade com a África terem sido cortados com a proibição do tráfico de escravos em 1850, e com o fim do comércio ilegal de africanos, que durou até 1870. Para ele, Salvador se mantinha como um espaço que cultuava as tradições trazidas da África novecentista, preservadas, portanto, das influe ências africanas contemporâneas. As críticas do scholar Herskovits referiam-se às atividades desenvolvidas por Verger, a partir de 1948, que สี restabeleciam o contato entre as duas margens do Atlântico, "destruindo", assim, um campo concebido como um "laboratório natural". Verger não esteve preocupado em manter a pureza de um campo, da mesma forma que não podem ser atribuídas a ele as diversas construções de Salvador que o sucederam.

${ }^{12}$ Sobre o tema, ver Guimarães, Antonio Sergio A. Comentários à correspondência entre Melville Herskovits e Arthur Ramos (1935-1941). http://www.fflch.usp.br/sociologia/asag/Coment\%E1rios\%20\%E0\%20correspond\%EAncia\%20entre\%20Herslovits\%20e\%20Ramos.pdf. Acesso em 20/12/2013.

${ }^{13}$ Para uma análise desse debate e suas repercussões no Brasil, ver Sansone (2012).

\section{A COLEÇÃO DE FOTOGRAFIAS DE PIERRE VERGER}

Na Fundação Pierre Verger, há cerca de 500 fotografias do artista sobre o Rio de Janeiro. O maior conjunto, com mais de 100 fotos, está associado ao carnaval de rua de 1941. Havia, naquela época, dois tipos de carnaval: o dos clubes e o das ruas. Verger interessou-se pelo segundo, onde encontrou homens negros fantasiados de mulher, e pelos blocos, em que os homens vestiam saias de palha procurando imitar as dançarinas havaianas. Há também em torno de 100 fotografias de paisagens da cidade. Dentre as restantes, as mais numerosas são aquelas tiradas da população de rua, em praias, no cais do porto, nas subidas dos morros cariocas e na Festa de São Jorge. Destacam-se ainda fotografias de objetos de origem africana encontrados no Museu Nacional e objetos religiosos no Museu da Polícia.

Ao procurar a fotografia da jovem bem vestida, que foi reproduzida na matéria de jornal e na exposição, verificamos que aquela não era apenas a fotografia de uma jovem que colocou sua roupa de domingo para ir ao parque. Tanto ela como o homem de terno que apareceram na matéria jornalística foram fotografados diversas vezes e suas fotos fazem parte de um

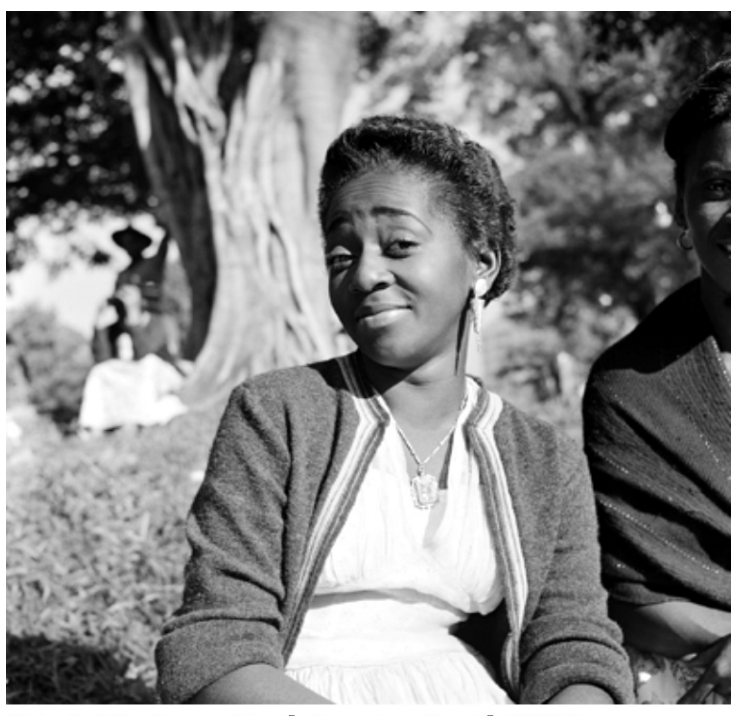

Foto 3: São Jorge, Rio de Janeiro, Brasil (1957) Pierre Verger(CFundação Pierre Verger. 
conjunto de 60 fotografias sobre a festa de São Jorge, na Praça da República, centro do Rio de Janeiro. A corrente no pescoço da jovem traz uma medalha com a imagem do santo. Verger não estava à procura de passeios no parque, mas de festas religiosas.

Embora São Sebastião seja o padroeiro da cidade do Rio de Janeiro, São Jorge é o que tem maior popularidade. O Dia de São Jorge é comemorado no dia 23 de abril, e sua repercussão é tamanha, que se tornou feriado municipal em 2002. O culto a São Jorge é celebrado na cidade desde pelo menos o século XVIII, quando foi trazido pela monarquia portuguesa. ${ }^{14}$ Inicialmente, São Jorge saía à frente das procissões de Corpus Christi, ganhando, mais tarde, sua independência. São Jorge foi um soldado, imortalizado por ter sido torturado até a morte pelo Império Romano, por manter sua lealdade ao cristianismo. Conta ainda a lenda que o soldado matou um dragão com sua lança para salvar o sacrifício de uma princesa. $\mathrm{O}$ santo é representado por um guerreiro montado em um cavalo branco, matando um dragão com sua lança. No Rio de Janeiro, a irmandade de São Jorge abria suas portas tanto para homens livres como para mulheres, forros e escravos. Ele passou a ser venerado tanto no catolicismo como nas religiões afro-brasileiras. Nos rituais de umbanda, praticados no Rio de Janeiro, sua cor é o vermelho e ele é conhecido como Ogum, orixá guerreiro, protetor das pessoas fortes, impetuosas e impulsivas. Nas tradições afro-brasileiras, as manchas apresentadas pela lua são interpretadas como imagens do santo guerreiro, de seu cavalo e de sua espada.

Em suma, no dia de São Jorge, tem lugar a maior e mais popular festa religiosa na cidade do Rio de Janeiro, agregando padres e pais de santo, sendo que esses últimos dão passes gratuitamente a seus milhares de fiéis. Além das Igrejas dedicadas ao santo - Igreja de São Jorge, no Centro do Rio de Janeiro, e Paróquia de São Jorge, em Quintino -, há bandas de

${ }^{14}$ Sobre a importância da festa de São Jorge para a cidade do Rio de Janeiro, ver Pitrez, 2007. música, barraquinhas de comida e batucadas por toda a cidade. É inegável, portanto, que o olhar de Verger, ao chegar ao Rio de Janeiro, estava voltado para a população afrodescendente. Seu interesse pelos festejos dedicados a Ogum, divindade da cultura iorubá, conhecida na Bahia como nagô, não foi fortuito.

Embora considerando que imagens são selecionadas para além da intencionalidade de seu autor, procuramos investigar se havia relação entre as fotos de Verger e o contraste entre Rio de Janeiro e Salvador. Acompanhamos alguns momentos da trajetória do autor e suas conexões com nações africanas. É importante destacar que o interesse de Verger recaiu principalmente sobre a cultura iorubá, que, segundo ele, podia ser encontrada preservada no candomblé da Bahia. Nesses rituais, ele identificou diversos elementos da tradição Ketu, vila iorubá que faz parte do território do atual Benin, e que foi onde Verger se iniciou no Ifá e se tornou Fatumbi. O grupo linguístico banto, proveniente da África Central (Angola e Congo), não recebeu muita atenção do fotógrafo. Contudo, nas fotos do Rio de Janeiro, Verger procurava por remanescentes de tradições africanas. Priorizou festas religiosas, como a de S. Jorge, cenas de rua e blocos carnavalescos, em sua maioria constituídos por negros. Queremos dizer com isso que não há uma oposição entre os negros cariocas "ocidentalizados", distantes dos trajes tradicionais africanos, ou dos seus preceitos ou rituais, e os negros baianos de corpo nu que aparecem junto ao mar. $\mathrm{O}$ sentido de raiz, ou de pureza africana, não fez necessariamente parte do olhar de Verger, que trabalhou com as noções de fluxo e refluxo.

As fotografias do Rio de Janeiro, ao serem expostas contemporaneamente em hotéis e outros pontos turísticos, representam uma africanidade cifrada, uma vez que ela é apagada pelos estereótipos e tipos urbanos criados na cidade. As fotografias de Salvador, por outro lado, trazem os sinais da África mais visíveis, ou seja, o candomblé com seu vestuário, canções, culinária, ritos e segredos. Essas são 
marcas que têm sido reiteradas e reinventadas nas últimas décadas, na construção política e econômica de cidades que se tornaram símbolos seja da "mestiçagem", seja da "africanidade”. Para evitar esses dualismos, é interessante lembrar que a "Maria Lata D’água”, representada como um tipo carioca, traz elementos de uma prática bastante presente na África, tanto antiga, como contemporânea, que é a de carregar objetos na cabeça. Mais do que mero hábito utilitário, esse costume está presente em práticas rituais. É o que mostra o quadro exibido no Museu Nacional do Gana. Nele, uma rainha coloca pequenos vasos sobre as cabeças de jovens enfileiradas como parte de um ritual de iniciação.

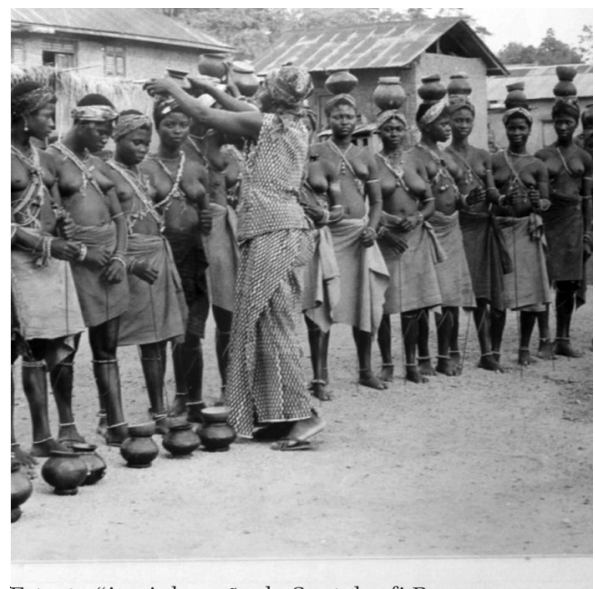

Foto 4 : “A rainha-mãe de Santokrofi Benua Mama Yassi iniciando as moças no rito Parkafor". Acervo do Museu Nacional de Gana. [Reprodução fotográfica feita por Mauricio Barros de Castro]

\section{CONCLUSÃO}

As reflexões sobre o olhar estrangeiro têm sido frequentes nas últimas décadas, \& principalmente a partir da crítica à formação a de um imaginário repleto de exotismo e sen今 sualidade associado aos trópicos. Ao longo do artigo, procuramos também ressaltar as diversas apropriações que são feitas desses registros. Não é, portanto, exagero afirmar que o problema das representações, usos e abusos da imagem ao longo dos séculos permanece como foco importante para se entender a história das relações raciais no país. Ainda que tenhamos uma diversidade de imagens referente a três séculos de registro do negro no Brasil, do XVII ao XIX (Moura, 2000), a sensação mais comum transmitida pelo encontro entre estrangeiros e descendentes de africanos tem sido a de desconforto latente.

No século XIX, aqueles que chegaram à cidade do Rio de Janeiro não economizaram seus elogios à natureza deslumbrante, que incluía a mata e, muitas vezes, os povos indígenas. O mesmo não acontecia na descrição dos escravos. Na missão composta por artistas franceses, na década de 1820, destacaram-se as obras de Jean-Baptiste Debret e Johann Moritz Rugendas. Não se pode negar que é muito mais conhecida no país a imagem de Debret, que mostra um indivíduo levando chibatadas no Pelourinho, chamada Açoite, do que outra que mostra um grupo festivo tocando instrumentos musicais num cortejo de domingo, intitulada Marimba. No período republicano, em que a escravidão já havia sido abolida, manteve-se, para descrição da escravidão, a ênfase nas imagens que reproduziam os castigos e mutilações impostos aos corpos dos indivíduos escravizados. Não se trata de amenizar o passado violento da escravidão, mas de apontar os processos seletivos de fotografias no período pós-abolicionista.

Contemporaneamente, abre-se espaço para a interpretação de outras realidades, que incluem a capacidade de organização daqueles que foram escravizados, em torno da festa, da religião, de quilombos, de maltas de capoeira e outras associações que possibilitaram não apenas a resistência, como a própria abolição da escravatura. Somente a partir de trabalhos interessados na cultura popular afrodescendente - como o lundu, o batuque, o jongo, a capoeira e o samba - que novas imagens sobre o sistema escravista no período colonial passaram a ganhar destaque. ${ }^{15} \mathrm{Na}$ última década, tornaramse visíveis as gravuras de Rugendas, de 1835,

${ }^{15}$ Ver, por exemplo, o estudo de Martha Abreu (1999) sobre a Festa do Divino, em que são utilizadas três pranchas de Rugendas para mostrar as distinções entre o lundu e o batuque. 
chamadas San Salvador e Jogar Capoeira, que mostram, de perspectivas distintas, a prática da luta e dança que se tornou símbolo de resistência à escravidão.

Essa mudança do olhar para o passado colonial e seu sistema escravista deve muito aos trabalhos de Pierre Verger, que se inseriu no debate racial, inicialmente, com um conjunto importante de imagens sobre práticas religiosas, e, logo depois, com uma tese e vários artigos sobre os fluxos migratórios e o intercâmbio cultural entre Benin e Salvador. Embora nem a matéria jornalística nem a exposição do Copacabana Palace tenham destacado a importância da cultura africana no cotidiano das duas cidades, ainda que com suas especificidades, certamente esse foi o ponto de partida do fotógrafo.

No Brasil contemporâneo, a reprodução e a seleção de imagens sobre a população afrodescendente apresentadas ao grande público acontecem, na maioria das vezes, a partir de perspectivas que criam estereótipos, infantilizam indivíduos e tornam invisível a questão racial. $\mathrm{Na}$ matéria jornalística que deu início a este artigo, observamos o último caso. Nela, não estava posta a oposição entre duas cidades, mas a invisibilidade da negritude, que certamente está relacionada ao racismo à brasileira. Em oposição ao olhar de Verger, que estava interessado em destacar, de forma positiva, a presença de práticas, hábitos, movimentos e expressões de origem africana no Brasil, a matéria traduz aquelas imagens como "tipos urbanos". Independentemente do fotógrafo e de sua obra, que apesar de ganharem significados distintos ao longo do tempo, foram responsáveis pelo fortalecimento de um novo olhar sobre a questão racial no Brasil, invertendo a valorização negativa atribuída a algumas práticas e retirando da invisibilidade muitas outras, continuamos a conviver, no Brasil, com silêncio e estereótipos nas representações que temos de populações afro-brasileiras.

Recebido para publicação em 13 de agosto de 2014 Aceito em 23 de novembro de 2014

\section{REFERÊNCIAS}

ABREU, Martha. O Império do Divino: festas religiosas e cultura popular no Rio de Janeiro. Rio de Janeiro: Editora Nova Fronteira, São Paulo: Fapesp, 1999.

ALENCASTRO, Luís Felipe. O trato dos Viventes. A Formação do Brasil no Atlântico Sul. São Paulo, Companhia das Letras, 2000.

BARADEL, Alex. Um Fotógrafo Livre. In LODY, Raul; Baradel, ALEX (eds). O olhar viajante de Pierre Verger. Salvador: Fundação Pierre Verger, 2002. p. 18-23.

BASTIDE, Roger; FERNANDES, Florestan. Relações raciais entre negros e brancos em São Paulo. São Paulo, Anhembi, 1955.

Mouton, 1958.

Le Candomblé de Bahia (rite Nagô). Paris:

Les religions africaines au Brésil. Paris: Presses Universitaires de France, 1960.

FUNDACÃO PIERRE VERGER. Caribé, Verger \& Jorge: Obás da Bahia. Salvador: Fundação Pierre Verger/Lauro de Freitas: Sisluna Editora, 2012.

HAMY, E.T. Les origines de Musée d'ethnographie, histoire et documents. Paris: Ernest Leroux Éditeur, 1890. Disponvel em: http://archive.org/stream/lesoriginesdumus01hamy. Acesso em: 11 jul. 2013.

LAURIÈRE, Christine. Paul Rivet (1876-1958), le savant et le politique. Nuevo Mundo Mundos Nuevos, 2007. Disponível em: http://nuevomundo.revues.org/3365. Acesso em: 11 jul. 2013.

LIENHARD, Martin. Sergio Santimano: o Moçambique dos "pobres" ou a escola da vida. In:_(org.) Discursos sobre (l)a pobreza: America Latina y/e países luso-africanos. Madrid: Iberoamericana, p. 217-224, 2006.

LODY, Raul. O olhador do mundo. In: LODY, Raul; BARADEL, Alex (eds). O olhar viajante de Pierre Verger. Salvador: Fundação Pierre Verger, 2002. p. 10-15.

LÜHNING, Angela E. Pierre FatumbiVerger e sua Obra. Afro-Ásia, n. 21, 1998-9. p. 315-364.

Uma biografia diferente. In: LODY, Raul; BARADEL, Alex (eds). O olhar viajante de Pierre Verger. Salvador: Fundação Pierre Verger, 2002. p. 201-203.

. (Org). Verger-Bastide: dimensões de uma amizade. Rio de Janeiro: Bertrand Brasil, 2002a.

. Pierre Verger: repórter fotográfico. Rio de Janeiro: Bertrand Brasil, 2004.

MAIO, Marcos Chor. O projeto UNESCO e a agenda das ciências sociais no Brasil dos anos 40 e 50. Revista Brasileira de Ciências Sociais, n. 41, 1999. p. 141-158.

MOURA, Carlos Eugênio Marcondes de. A travessia da Calunga Grande: três séculos de imagens sobre o negro no Brasil. São Paulo: Edusp, 2000.

MÉTRAUX, Alfred; VERGER, Pierre. Le pied à l'étrier. Correspondance 1946-1963. Paris: Éditions Jean-Michel Place, 1994.

O GLOBO, Segundo Caderno, Coluna Gente Boa. 16. mar. 2013. p. 3 .

PEIXOTO, Fernanda Arêas. Diálogos brasileiros: uma análise da obra de Roger Bastide. São Paulo: Edusp/Fapesp, 2000.

PITREZ, Maria Cláudia. 23 de Abril - festa de São Jorge: um estudo sobre a oficialização da festa de um dia santo em feriado municipal na cidade do Rio de Janeiro. Rio de Janeiro: UFRJ/IFCS (dissertação de mestrado no Programa de Pós-Graduação em Sociologia e Antropologia), 2007. 
REGO, Waldeloir. A Bahia de Pierre Verger. Exu, n. 33, maio/jun, v. 6, p. 10-17, 1993.

SANSONE, Livio. Estados Unidos e Brasil no Gantois: o poder e a origem transnacional dos estudos afrobrasileiros. Revista Brasileira de Ciências Sociais, n. 79, p. 9-29, 2012.

SOUTY, Jérome. Pierre Fatumbi Verger: do olhar livre ao conhecimento iniciático. São Paulo. Ed. Terceiro Nome, 2011.
VERGER, Pierre. "Coco belefó". Bric a Brac, IV. Brasília, 1990, apud Lody, Raul. "O Olhar do Mundo". In: LODY, Raul; BARADEL, Alex (eds). O olhar viajante de Pierre Verger. Salvador: Fundação Pierre Verger, 2002. p. 11.

Flux e reflux de Le traitedesesclaves entre le Golfe duBéninet Bahia de Todos os Santos, dudix-septièmeaudixneuvièmesiècle. Paris: Mouton, 1968. 
ONE VERGER, TWO LOOKS: the construction of Brazilian africanity by a foreigner

\author{
Maurício Barros de Castro \\ Myrian Sepúlveda dos Santos
}

Over the last decades a reflection upon the foreign look has become frequent, mainly from the point of view of critics to the creation of an imaginary filled with exoticism and sensuality associated to the tropics. So it is not an exaggeration to state that the problems with the representations, uses and overuses of the image of Brazilian afro-descendants throughout the centuries is still an important focus for understanding the history of racial relations in the country. However, it is not always that the exotic is sought in the tropics. This article analyzes the impact of the look of Pierre Verger on the construction of the African legacy in Brazil.

KeyworDs: Pierre Verger. Afro-descendants. Racial relationships.
UN PIERRE VERGER, DEUX REGARDS: la construction de l'africanité brésilienne par un étranger

\author{
Maurício Barros de Castro \\ Myrian Sepúlveda dos Santos
}

Les réflexions faites sur le regard étranger ont été fréquentes au cours des dernières décennies, surtout si l'on prend en considération les critiques sur la formation d'un imaginaire rempli d'exotisme et de sensualité associé aux tropiques. Il n'est donc pas exagéré de dire que le problème des représentations, de l'utilisation et des abus faits de l'image des descendants africains au Brésil, tout au long des siècles, constitue toujours un élément important pour la compréhension de l'histoire des relations raciales dans le pays. On n'est cependant pas toujours à la recherche de l'exotisme sous les tropiques. Cet article essaie d'analyser l'impact du regard de Pierre Verger sur la construction de l’héritage africain au Brésil.

Mots-CLÉs: Pierre Verger. Ascendance/Descendance africaine. Relations raciales.

Maurício Barros de Castro - Doutor em História Social. Professor do Instituto de Artes da Universidade
do Estado do Rio de Janeiro (UERJ). Desenvolveu projeto de pós-doutorado no Programa de Pós-graduação
em Ciências Sociais da UERJ, com bolsa da Fundação Carlos Chagas Filho de Amparo à Pesquisa no
Estado do Rio de Janeiro (FAPERJ). Faz parte do Grupo de Pesquisa "Arte, Cultura e Poder". Coordenador
do "Museu Afrodigital Rio". Desenvolve pesquisas sobre os seguintes temas: artes visuais, cultura
popular, patrimônio cultural e diáspora africana. Publicações recentes: Remembering and forgetting the
Kalunga Project: popular music and the construction of identities between Brazil and Angola. African
and Black Diaspora: An International Journal, v. 1, p. 1-13, 2015; Memoria do Projeto Kalunga no Museu
Afrodigital Rio de Janeiro: reflexões sobre identidades negras e africanas no Brasil. Revista Diversitas, v.
1, p. 126-150, 2014; Zicartola: política e samba na casa de Cartola e Dona Zica. Rio de Janeiro, Azougue
Editorial, 2013.
Myrian Sepúlveda dos Santos - Doutora em Sociologia. Professora da Universidade do Estado do Rio
de Janeiro. Coordenadora do Grupo de Pesquisa registrado no CNPq "Arte, Cultura e Poder" e do "Museu
Afrodigital". Sua área de pesquisa é a sociologia da cultura. Atualmente desenvolve uma investigação
sobre memória e trauma nas antigas prisões da Ilha Grande. Publicações recentes: Porões da República.
Rio de Janeiro: EDUERJ/Garamond, 2009); Memória Coletiva e Teoria Social. Coimbra: Imprensa da
Universidade de Coimbra, 2012, reedição; Memória Coletiva e Identidade Nacional. São Paulo: Editora
Annablume). 
